DOI: https://doi.org/10.36910/6775-2524-0560-2021-43-34

УДК 004.451

Мельник Василь Михайлович, к.ф.-М.н., доцент,

http://orcid.org/0000-0001-8282-6639

Багнюк Наталія Володимирівна, к.т.н., доцент,

http://orcid.org/0000-0002-7120-5455

Здолбіцька Ніна Василівна, к.т.н., доцент

https://orcid.org/0000-0002-1345-3581

Якимчук Тарас Петрович, магістрант

Луцький національний технічний університет

\title{
МЕТОДИ ПОБУДОВИ АДРЕСНОГО ПРОСТОРУ БЕЗПРОВІДНИХ СЕНСОРНИХ МЕРЕЖ
}

Мельник В.М., Багнюк Н.В., Здолбіцька Н.В., Якимчук Т.П. Методи побудови адресного простору безпровідних сенсорних мереж. У даній роботі розглянуто основні задачі та проблеми побудови бездротових сенсорних мереж. Оглянуто переваги й недоліки запропонованих рішень алгоритму побудови та адресації. 3'ясовано, що на сьогодні не існує ідеального алгоритму адресації у безпровідних сенсорних мережах. В роботі наведено лише малу частину існуючих рішень для бездротових сенсорних мереж. Однак, велика кількість досліджень у цьому напрямку свідчить про необхідність отримання оптимального алгоритму побудови адресного простору для безпровідних мереж давачів.

Ключові слова: сенсорна мережа, бездротова мережа давачів, адресний простір, адресація.

Мельник В.М., Багнюк Н.В., Здолбицкая Н.В., Якимчук Т.П. Методы построения адресного пространства беспроводных сенсорных сетей. В данной работе рассмотрены основные задачи и проблемы построения беспроводных сенсорных сетей. Осмотрено преимущества и недостатки предложенных решений алгоритма построения и адресации. Выяснено, что на сегодня не существует идеального алгоритма адресации в беспроводных сенсорных сетях. В работе приведено лишь малую часть существующих решений для беспроводных сенсорных сетей. Однако, большое количество исследований в этом направлении свидетельствует о необходимости получения оптимального алгоритма построения адресного пространства для беспроводных сетей давателей.

Ключевые слова: сенсорная сеть, беспроводная сеть датчиков, адресное пространство, адресация.

Melnyk V., Bahniuk N., Zdolbitska N., Yakimchuk T. Methods for constructing the address space for wireless sensor networks. This paper studies the main tasks and problems of building the wireless sensor networks. The advantages and disadvantages of the proposed solutions of the construction and addressing algorithm are considered. It has been found that there is currently no perfect addressing algorithm in wireless sensor networks. The paper presents only a small part of the existing solutions for wireless sensor networks. However, a large number of studies in this direction indicates the real need to obtain an optimal algorithm to construct the address space for wireless sensor networks.

Keywords: sensor network, wireless sensor network, address space, addressing.

\section{Вступ}

В наш час бездротова мережа давачів (БМД) збоку постачальників Інтернет (англ. wireless sensor network, WSN) - це мережа, яка складається із сенсорів, має властивість самоорганізації та служить для моніторингу різних процесів. Така мережа може покривати від декількох метрів до десятків кілометрів площі користувачів.

Базова станція (БС) або приймач відіграють роль інтерфейсу між діючою мережею і користувачами. Якщо ввести запит і зібрати результати від приймача, то можна отримати всю необхідну інформацію 3 мережі. Мережа БСМ може інтегрувати в собі сотні тисяч сенсорів, які можуть між собою зв'язуватися через радіосигнали. Безпровідний сенсор оснащений сенсорами, обчислювальними пристроями, радіоприймачами і компонентами живлення.

Сфера використання залежить від типу сенсора. Загалом така мережа являє собою певну кількість пристроїв, пов'язаних між собою та/або базовою станцією через радіосигнали. Кожен пристрій, який називається мот, містить накопичувач даних, обчислювальний модуль, радіо-модуль i, власне, давач та елемент живлення. Сенсор обирається в залежності від цілей: температурний, датчик вологості, руху, освітлення та інші.

Основним проблемним місцем є живлення цих пристроїв, оскільки після активації вони повинні залишатися тривалий час автономними. 3 цією метою використовуються невеликі батареї, а рідше сонячні елементи. Саме тому постає питання розробки алгоритмів управління сенсорними мережами, у яких буде максимально оптимізоване енергоспоживання. Поряд 3 цим виникає проблема раціоналізації процесів, що виконуються на вузлах мережі. Також одним із основних питань $є$ безпека такої мережі та засоби ії захисту. 
Загалом можна сформулювати наступні якості побудови бездротової сенсорної мережі: легкість та комфортність початкового їі налаштування, максимізація енергоефективності, підтримка їі цілісності після виходу з ладу певних вузлів.

Із другого пункту також можна виокремити дві підзадачі: 1) точне та швидке визначення вузла у мережі та просторі; 2) мінімізація інформації передавання. Точна та швидка ідентифікація вузла в мережі - це критерії, які необхідні для ефективної маршрутизації. Ідентифікація, у свою чергу, забезпечує енергоефективність передачі даних та їх надійну доставку до кінцевого користувача.

\section{Особливості самооранізовуючих мереж}

У нинішній телекомунікації велика роль належить радіомережам 3 самоорганізацією (selforganizing). Уже $з$ назви видно, що побудова радіомережі з самоорганізацією надає можливість створення бездротової мережі без або з мінімальною участю людини. Дана архітектура була названа «ad-hoc», або мережі, створені для певних цілей [0]. Характерними особливостями архітектури таких мереж є: зміна розмірності чи кількості вузлів мережі і площа покриття, мобільність і стаціонарність вузлів, випадковість мережевої топології, іiі динамічність і неоднорідність, організація передачі інформації через комутацію пакетів з застосуванням багатострибкової маршрутизації на кожному 3 мережевих вузлів, децентралізований типу управління з дотриманням автономності вузлів у роботі без фіксації будь-якої мережевої інфраструктури, динамічність і ненадійність радіо-ресурсу, колективне його використання та зміни продуктивності мережевих каналів і вузлів, масштабованість в легкому нарощенні і зміні кількості вузлів, обмеженість вузлових ресурсів, обмежена безпека обумовлена обмеженнями фізичної безпеки радіоканалу.

Реальна природа радіоканалу дає можливість зловмисникові застосовувати активні і пасивні мережеві перешкоди, прослуховувати передавання вузлів, проводити аналіз мережевого трафіку та розкривати існуючу систему мережевого управління. Динаміка топології та інтегрована робота вузлів допускають вразливість функціонування мережевих протоколів на канальному, мережевому й інших рівнях моделі взаємодії подібних відкритих систем. Зростаючий інтерес до безпровідних мереж призвів до появи стандартизації [2-5] та окремих технологій застосування на фізичному і канальному рівнях для сьогоднішніх комп'ютерів, таких як Bluetooth, IEEE 802.11 різних версій, HiperLan й інших. Однак ці протоколи i стандарти не враховують тонкощів побудови та функціонування мереж із самоорганізацією.

Швидкий розвиток елементної бази та зростання обчислювальних можливостей на сьогодні визначили широкий спектр сфер застосування MCP: мережі ad-hoc з випадковими проте стаціонарними користувачами; мобільні радіомережі з реалізацією повністю децентралізованого управління без базових станцій, мережі зонової структури зі створенням безпровідної магістралі і зони обслуговування мобільних/стаціонарних абонентів 3 доступом до маршрутизатора, сенсорні мережі 3 малогабаритних сенсорних вузлів та функціями моніторингу відповідних зовнішніх параметрів, обробки і передачі даних по каналах радіозв'язку, автомобільні та гібридні мережі з наявністю спільного функціонування згаданих вище мереж.

Отже, у наш час мобільні та безпровідні технології забезпечують глобальне покриття з метою передачі даних і на основі них розвиваються різні види технологій призначених для спілкування стаціонарних та мобільних абонентів. Сьогодні системи мобільного і безпровідного зв'язку орієнтовані на створення центрів користувачів й базуються на об'єднанні різних за типом систем доступу із метою утворення уніфікованого середовища з комутацією пакетів. Основним для користувача $є$ отримання різноманітних послуг, мультимедійних пакетів і різноманітного контенту через різні системи доступу та пристрої. I незважаючи на значний прогрес побудова МСР залишається невирішеною, а також проблеми ії створення та експлуатації.

\section{Теоретичні основи побудови адресного простору БМД}

Дослідження БСМ у своїй більшості брали до уваги однорідні сенсори, однак в наш час активні дослідницькі роботи ведуться з метою вивчення гетерогенних сенсорних мережах [6], в яких сенсори різняться своєю енергією один від одного. Паралельно досліджується і проблема розгортання сенсорів ретранслятора, який забезпечує відмовостійкість мережі з більш високим ії підключенням в цілісну систему гетерогенних безпровідних сенсорних мереж, в якій сенсори володіють різними радіусами передавання. Сьогоденні мережеві архітектури саме з гетерогенними пристроями і швидке просування в цьому напрямку мережевої технології усувають існуючі обмеження, значно розширюючи діапазон можливих програм для БСМ.

Найбільш розповсюдженими протоколами, що використовуються для вирішення задач БМД є протоколи, які підтримуються і розвивається альянсом ZigBee. Мережі ZigBee - це мережі із 
самоорганізацією та самовідновленням. Оскільки ZigBee-пристрої при вмиканні живлення, завдячуючи вбудованому програмному забезпеченню, вміють самостійно знаходити один одного й формувати мережу, а у разі поломки одного із вузлів можуть відшукувати і встановлювати нові маршрути задля передачі даних.

Розглядаючи стандарт ZigBee, призначений для формування загального поняття про побудову адресного простору в бездротових сенсорних мережах, існує два принципових механізми побудови адресного простору - стохастичного та розподіленого присвоювання адрес. Для обох цих механізмів характерним $є$ те, що кожен батьківський вузол самостійно призначає адреси для дочірніх вузлів, без потреби взаємодії із мережевим координатором.

Стохастична адресація (алгоритм SAAM, Stochastic Address Assignment Mechanism) полягає у присвоюванні випадкової адреси новим вузлам. Адресація не є ієрархічною, тому при додаванні нового пристрою до мережі потрібно проводити перевірку на дублювання адрес, щоб не виникало конфліктів. При конфлікті адрес пристрій повинен перепідключитися до мережі для отримання нової адреси. Структура дерева не доступна для маршрутизації SAAM. Така адресація не прийнятна для сенсорних мереж малої потужності, тому що вимагає частої трансляції пакетів із заголовками великого розміру, а також протоколи маршрутизації ODRP та TDRP, які застосовуються тут, потребують додаткової передачі необхідної службової інформації та зберігання великих таблиць маршрутизації [7].

Розподілена адресація за алгоритмом DAAM (Distributed Address Assignment Mechanism) полягає у побудові деревоподібної мережі. Унікальність присвоєних адрес забезпечує функція CSkip. Попередня побудова маршрутів та таблиць маршрутизації у даному методі не потрібна. Разом із функцією CSkip та деревоподібною топологією у DAAM методі з'являються такі поняття як максимальна глибина дерева $\mathrm{L}_{\mathrm{m}}$, максимальна кількість нащадків $\mathrm{C}_{\mathrm{m}}$ та максимальне число нащадків які можуть виступати роутерами $\mathrm{R}_{\mathrm{m}}$. Батьківський вузол використовує ці параметри для обчислення функції (1) CSkip з метою знаходження розмірів адресних пулів для вузлів-нащадків [8].

$$
\begin{gathered}
\text { CSkip }=\{1+C m *(L m-d-1)\} \text { if Rm }=1 \ldots(a) \\
=\left\{1+C m-R m-C m *\left[R m^{\wedge}(L m-d-1]\right) / 1-R m\right\}
\end{gathered}
$$

$\operatorname{CSkip}(d)$ - це значення глибини батьківського елемента. Припустимо, що батьківський вузол на глибині $d$ має адресу $A_{p}$. Тоді $n$-му нащадку-роутеру надається адреса:

$$
A p+(n-1) \times \operatorname{CSkip}(d)+1,
$$

а $n$-му нащадку-кінцевому пристрою присвоюється адреса:

$$
A p+R m \times \operatorname{CSkip}(d)+n
$$

При використанні методу DAAM важко отримати велику площу покриття мережею, оскільки при певних заданих початкових параметрах мережа швидко досягатиме лімітів підключення, так як вузли можуть ставати як дочірніми одному батьківському, так і батьківськими - наступному вузлу, побудувавши лінійний ланцюг і заповнивши глибину дерева [9]. Наприклад, при початкових параметрах $L_{m}=4, C_{m}=3, R_{m}=3$, може виникнути проблема, коли мот хоче підключитися до ближнього роутера, але той уже має максимум нащадків. 


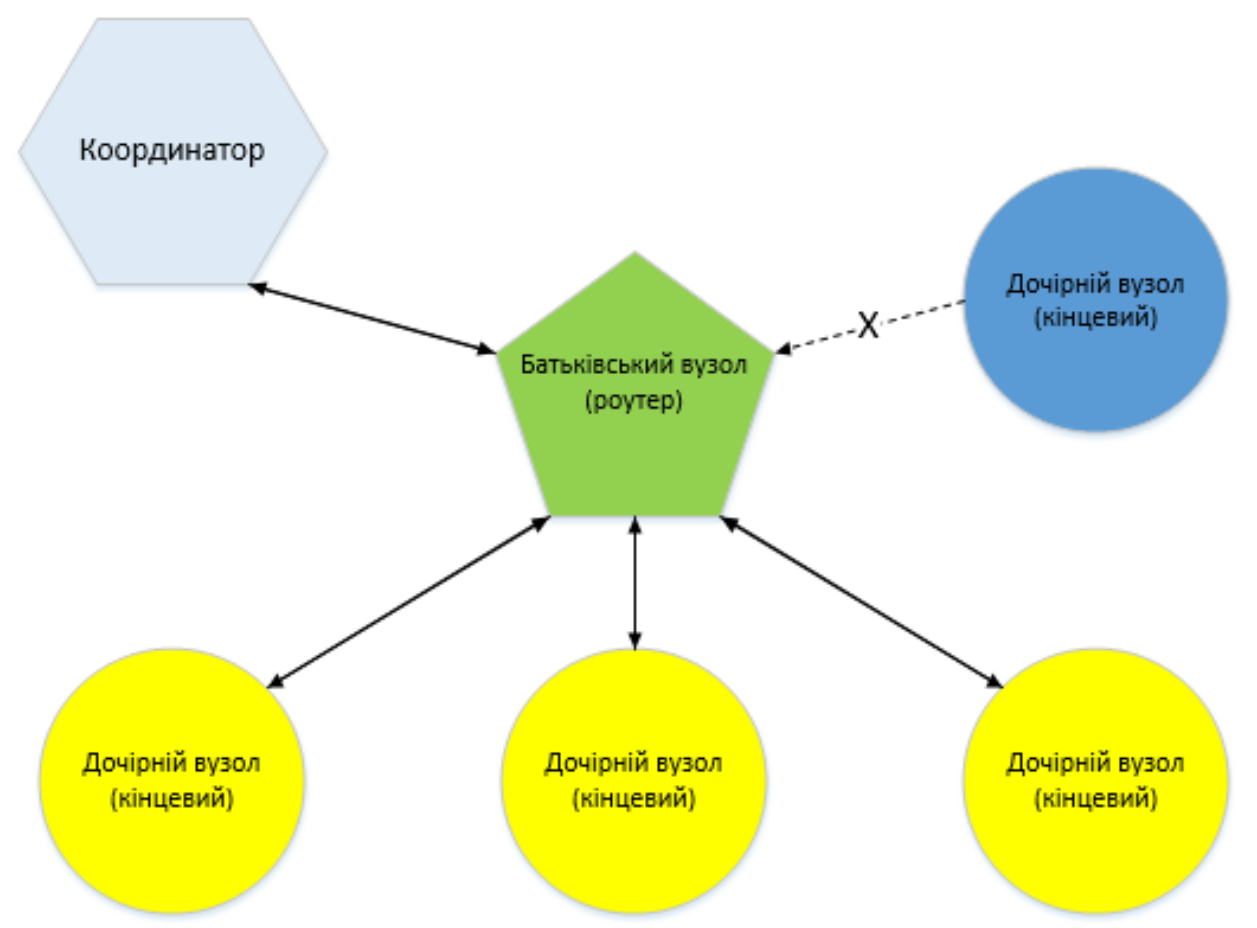

Рис. 1.1 - Проблема надання адреси новому моту в DAAM

\section{Обговорення проблем основних методів}

В наш час пропонується усе більше і більше алгоритмів, які можуть компенсувати недоліки двох попередніх. Наприклад алгоритм DIBA (Distributed Borrowing Addressing) - це розподілена адресація запозичених адрес. Даний метод вирішує проблему, коли адреса не може бути призначена новому моту, через досягнення ліміту підключених нащадків. Батьківський вузол-роутер посилає повідомлення, що хоче запозичити адресу. Отримавши дане повідомлення, дочірній кінцевий вузол записує адресу, якою він поділився з батьківським, оновлює власну таблицю маршрутизації. Далі батьківський вузол-роутер надає запозичену адресу моту, що бажає приєднатися [10].

Механізм конкуренції за керівництво кластером (cluster-head competitive mechanism) надає вирішення проблеми енерго-використання шляхом підрахунку споживання енергії [11]. Коли заряд певного батьківського вузла стане меншим за поточне середнє значення, координатор оголошує вибори нового батьківського вузла. Новим батьківським вузлом стане мот із найбільшим запасом енергії. Вузли із зарядом, меншим ніж поточне середнє значення, будуть проігноровані координатором, оскільки вони споживають забагато енергії. Новообраний батьківський вузол починає транслювати свій ID-номер, очікуючи під'єднання решти мотів і розподіляє ним адреси [11].

Існує багато інших алгоритмів та методів побудови адресного простору в безпровідних сенсорних мережах, такі як: алгоритм динамічного виділення адрес для контролю та управління БМД, Принцип маршрутизації та адресації без підтримки стану БМД, алгоритми побачення (рандеву) для БМД із мобільними базовими станціями, покращений алгоритм маршрутизації на базі оптимізації колонії мурашок у БМД та покращений алгоритм локалізації на основі генетичного алгоритму в БМД.

Можна сформувати наближену методику для вибору варіанту і побудови сенсорної мережі 3 наперед відомим призначенням, яка дозволяе підходом підбору технологій, варіантів побудови безпровідної сенсорної мережі та розрахунку технічних характеристик і параметрів експлуатації виконати вибір найбільш раціонального варіанту створення сенсорної мережі. Мета побудови сенсорної мережі та вибір їі раціонального підходу реалізації для заздалегідь відомчого призначення полягає в ефективному автоматизованому управлінні конкретної сфери чи виду діяльності.

Під терміном ефективно необхідно розуміти отримання найкращого результату комунікації в залежності від використання наявних ресурсів. Основні вузлові етапи реалізації цієї методики поднюють в собі формування цілей БСМ для реалізації відповідних завдань відомчого призначення, визначення стартових даних, чіткий аналіз уже діючих технологій БСМ і виділення найбільш придатної з них. Якщо технологія вибрана, то вона ухвалюється як найкраща і найраціональніша технологія для успішного виконання накреслених завдань відповідно до поставлених цілей. Далі слід вибрати частотний діапазон та перевірити електромагнітну сумісність (ЕМС), процес перевірки якої 
закінчується тоді, коли чітко визначається здатність одночасного функціонування радіоелектронних засобів і випромінювальних пристроїв з очікуваною якістю в реально діючих умовах їх експлуатації та з урахуванням впливу випадкових радіоперешкод без створення недопустимих таких перешкод для інших радіоелектронних засобів під час їх роботи.

Наступними кроками $є$ формування структури БСМ для наміченого призначення, вибір способу реалізації інформаційної безпеки в сенсорній мережі, узгодження та утвердження використовуваних топологій в БСМ, вибір робочих протоколів для передачі даних, чіткий розрахунок параметрів впливу на енергоресурси та їх мінімізацію, проведення розрахунку технічно-експлуатаційних параметрів та характеристик $n$-го варіанту побудови БСМ. Слід також розрахувати час (тривалість) побудови БСМ для реалізації поставленої мети, виконати запис отриманих робочих результатів для $n$-го варіанту побудови БСМ в відповідну базу даних. При цьому слід переглянути всі розглянуті варіанти побудови БСМ. Наступним $\epsilon$ остаточний вибір найбільш раціонального варіанту побудованої БСМ за $k$-тим критерієм, який і затверджується прийняттям відповідних рішень на реалізацію такої побудови БСМ відповідно до ухваленого варіанту. Якщо подібне рішення приймається, то надалі розробляються проект та різні види документації і виконується побудова БСМ.

Застосування даного методичного опису наполягає на чіткості формування мети та кроків реалізації. Він допоможе розробникам переглянути найбільш можливі варіанти побудови мережі, не затрачати зайвий час та кошти, а також передбачити структурні та функціональні переваги для ефективного досягнення поставленої мети.

\section{Висновок}

У статті було обговорено вагомі завдання та проблематику побудови бездротових сенсорних мереж. Здійснено також огляд основних понять та принципів, з'ясовано переваги й недоліки запропонованих рішень в побудові безпровідних сенсорних мереж. Однак, можна сказати, що сьогодні ще не існує якогось єдиного ідеального алгоритму адресації та підходу реалізації у розробці алгоритмів побудови сенсорних мереж. Дане питання більш опирається на цілі їх застосування та види виконання сервісу.

Нами наведено тільки частину пророблених завдань для побудови бездротових сенсорних мереж. Однак, велика кількість досліджень в наш час у даному напрямку говорить про актуальність даної проблеми та отримання більш оптимального алгоритму та підходу для побудови адресного простору та безпровідних мереж давачів.

Список бібліографічного опису.

1. Chai K Toh. Ad Hoc Mobile Wireless Networks: Protocols and Systems / Chai K Toh., 2002.

2. IEEE Std 802.11-1999 Edition (Reaff 2003), Information technology - Telecommunications and information exchange between systems - Local and metropolitan area networks - Specific requirements - Specifications.

3. IEEE Std 802.11a-1999 (Reaff 2003), Supplement to IEEE Standard for Information technology - Telecommunications and information exchange between systems - Local and metropolitan area networks - Specific requirements.

4. IEEE Std 802.11b-1999, Supplement to IEEE Standard for Information technology - Telecommunications and information exchange between systems - Local and metropolitan area networks - Specific requirements.

5. IEEE Std 802.11g-2004, IEEE Standard for Information technology - Telecommunications and information exchange between systems - Local and metropolitan area networks - Specific requirements - Specifications.

6. X. Han, X. Cao, E. L. Lloyd and C. Shen, "Fault-Tolerant Relay Node Placement in Heterogeneous Wireless Sensor Networks", IEEE Transaction on Mobile Computing, Vol. 9, No. 5, May 2010.

7. Address assignment for wireless sensor networks in mines / [N. El Rachkidy, A. Guitton, B. Bakhache та ін.].

8. Nikunj S. Review on address assignment mechanism in ZigBee wireless sensor networks / S. Nikunj, J. Shraddha.. - (Vol. 2 Issue 11).

9. Chun-Hsien Wu. Heterogeneous Wireless Sensor Network Deployment and Topology Control Based on Irregular Sensor Model / Chun-Hsien Wu, Yeh-Ching Chung. - Taiwan: Department of Computer Science, National Tsing Hua University, Hsinchu 30013.

10. Distributed Borrowing Addressing Scheme for ZigBee/IEEE 802.15.4 Wireless Sensor Networks / [P. Sungjin, J. Eun, H. Jae тa iн.].

11. An optimized cluster structure routing method based on leach in wireless sensor networks / [X.-X. Ding, M. Ling, Z.-J. Wang Ta iн.].

\section{References}

1. Chai K Toh. Ad Hoc Mobile Wireless Networks: Protocols and Systems / Chai K Toh., 2002.

2. IEEE Std 802.11-1999 Edition (Reaff 2003), Information technology - Telecommunications and information exchange between systems - Local and metropolitan area networks - Specific requirements - Specifications.

3. IEEE Std 802.11a-1999 (Reaff 2003), Supplement to IEEE Standard for Information technology - Telecommunications and information exchange between systems - Local and metropolitan area networks - Specific requirements.

4. IEEE Std 802.11b-1999, Supplement to IEEE Standard for Information technology - Telecommunications and information exchange between systems - Local and metropolitan area networks - Specific requirements.

5. IEEE Std 802.11g-2004, IEEE Standard for Information technology - Telecommunications and information exchange between systems - Local and metropolitan area networks - Specific requirements - Specifications. 
6. X. Han, X. Cao, E. L. Lloyd and C. Shen, "Fault-Tolerant Relay Node Placement in Heterogeneous Wireless Sensor Networks", IEEE Transaction on Mobile Computing, Vol. 9, No. 5, May 2010.

7. Address assignment for wireless sensor networks in mines / [N. El Rachkidy, A. Guitton, B. Bakhache та ін.].

8. Nikunj S. Review on address assignment mechanism in ZigBee wireless sensor networks / S. Nikunj, J. Shraddha.. - (Vol. 2 Issue 11).

9. Chun-Hsien Wu. Heterogeneous Wireless Sensor Network Deployment and Topology Control Based on Irregular Sensor Model / Chun-Hsien Wu, Yeh-Ching Chung. - Taiwan: Department of Computer Science, National Tsing Hua University, Hsinchu 30013.

10. Distributed Borrowing Addressing Scheme for ZigBee/IEEE 802.15.4 Wireless Sensor Networks / [P. Sungjin, J. Eun, H. Jae ta ін.].

11. An optimized cluster structure routing method based on leach in wireless sensor networks / [X.-X. Ding, M. Ling, Z.-J. Wang тa ін.]. 